\title{
Pembrolizumab-induced hypothyroidism caused reversible increased serum creatinine levels: a case report
}

\author{
Natsumi Matsuoka' ${ }^{1}$, Kenji Tsuji ${ }^{1 *}$, Eiki Ichihara², Takayuki Hara', Kazuhiko Fukushima'', Kishio Toma', \\ Shinji Kitamura ${ }^{1}$, Kenichi Inagaki ${ }^{1}$, Hitoshi Sugiyama ${ }^{3}$ and Jun Wada ${ }^{1}$
}

\begin{abstract}
Background: The advent of immune checkpoint inhibitors (ICls) has significantly improved the prognosis of patients with advanced malignancies. On the other hand, these drugs might cause immune-related adverse events (irAEs) including endocrinopathies and nephropathies. Thyroid dysfunction is one of the most common irAEs. For ICls-induced nephropathies, most cases are due to tubulointerstitial nephritis, which might require steroid treatment. Here, we report a patient with non-small cell lung cancer treated with $\mathrm{ICl}$ who developed increased serum creatinine (s-Cr) levels due to ICls-induced hypothyroidism.

Case presentation: A 57-year-old Asian man with refractory non-small cell lung cancer under ICls therapy (pembrolizumab, an anti-programmed cell death-1 monoclonal antibody) developed increased s-Cr levels 5 months after the pembrolizumab initiation. His laboratory data, renal biopsy, and Gallium-67 scintigraphy findings denied pembrolizumab-induced tubulointerstitial nephritis. His renal function was correlated with thyroid function. Despite the increase of s-Cr levels, serum cystatin C levels were normal, which could be explained by the hypothyroidism. Levothyroxine treatment improved renal function as well as thyroid function. Then pembrolizumab was resumed, and both his thyroid and renal function remained normal level. Ultimately, we concluded that the increased s-Cr levels were caused by pembrolizumab-induced hypothyroidism.

Conclusion: All clinicians involved in ICl treatment need to recognize the possible increase in s-Cr levels caused by ICls-induced hypothyroidism, and we propose monitoring serum cystatin C levels to differentiate ICls-induced hypothyroidism from tubulointerstitial nephritis before invasive renal biopsies or steroid treatment, which are recommended by the prescribing information for pembrolizumab, are performed.
\end{abstract}

Keywords: Pembrolizumab, Hypothyroidism, Creatinine, Cystatin C

\footnotetext{
* Correspondence: gmd422036@s.okayama-u.ac.jp

${ }^{1}$ Department of Nephrology, Rheumatology, Endocrinology and Metabolism,

Okayama University Graduate School of Medicine, Dentistry, and

Pharmaceutical Sciences, 2-5-1 Shikata-cho, Okayama 700-8558, Japan

Full list of author information is available at the end of the article
}

(c) The Author(s). 2020 Open Access This article is licensed under a Creative Commons Attribution 4.0 International License, which permits use, sharing, adaptation, distribution and reproduction in any medium or format, as long as you give appropriate credit to the original author(s) and the source, provide a link to the Creative Commons licence, and indicate if changes were made. The images or other third party material in this article are included in the article's Creative Commons licence, unless indicated otherwise in a credit line to the material. If material is not included in the article's Creative Commons licence and your intended use is not permitted by statutory regulation or exceeds the permitted use, you will need to obtain permission directly from the copyright holder. To view a copy of this licence, visit http://creativecommons.org/licenses/by/4.0/ The Creative Commons Public Domain Dedication waiver (http://creativecommons.org/publicdomain/zero/1.0/) applies to the data made available in this article, unless otherwise stated in a credit line to the data. 


\section{Background}

Immune checkpoint inhibitors (ICIs) have been developed, and the advent of ICIs significantly improved the prognosis of patients with advanced malignancies. However, these drugs have been reported to lead to immune-related adverse events (irAEs), including endocrinopathies and nephropathies. Renal dysfunction occurs in $0.3 \%$ of the patients under the treatment of pembrolizumab, an antiprogrammed cell death-1 monoclonal antibody [1], and most reported cases are due to tubulointerstitial nephritis [2]. Here we describe a case of reversible increased serum creatinine (s-Cr) levels due to hypothyroidism caused by pembrolizumab.

\section{Case presentation}

A 57-year-old Asian man was diagnosed as lung adenocarcinoma with several bone metastasis (non-small cell lung cancer (NSCLC), T1cNOM1c stage IVB, epidermal growth factor receptor (EGFR): negative, anaplastic lymphoma kinase (ALK): negative, programmed death ligand 1 (PDL1) tumor proportion score: 5\%, Fig. 1a-c), and he was initially treated with cisplatin and pemetrexed for 4 months, followed by 2 nd line pembrolizumab treatment $(200 \mathrm{mg} / 3$ weeks). Although his lung tumor decreased in size, levels of s-Cr gradually increased (from $0.88 \mathrm{mg} / \mathrm{dl}$ to $1.49 \mathrm{mg} / \mathrm{dl}$ ) and the estimated glomerular filtration rate (eGFR) decreased (from $69.9 \mathrm{ml} / \mathrm{min} /$ $1.73 \mathrm{~m}^{2}$ to $39.3 \mathrm{ml} / \mathrm{min} / 1.73 \mathrm{~m}^{2}$ ) within 5 months after the pembrolizumab initiation (Fig. 2). According to the Keytruda $^{\circ}$ prescribing information [3], pembrolizumab was discontinued, and he was admitted to our hospital. At admission, his height was $172.8 \mathrm{~cm}$, his body weight was $88.1 \mathrm{~kg}$, and his body mass index was $29.4 \mathrm{~kg} / \mathrm{m}^{2}$. His body temperature was $36.4{ }^{\circ} \mathrm{C}$, his pulse was 67 per minute, and his blood pressure was $144 / 92 \mathrm{mmHg}$. There were no episodes of hypotension at home or office visit. Electrocardiogram and computed tomography (CT) analyses denied arrhythmia, myocarditis or pericarditis, which could influence renal perfusion. There was no elevation in the Creactive protein (CRP) levels. Despite the increase in $\mathrm{s}-\mathrm{Cr}$ levels, serum cystatin $\mathrm{C}$ (s-cystatin $\mathrm{C}$ ) levels were within the normal range $(0.81 \mathrm{mg} / \mathrm{L})$. 24-h creatinine clearance (Ccr) was $62.8 \mathrm{ml} / \mathrm{min}$ and urine creatinine was $1.8 \mathrm{~g} /$ day. Antinuclear and antineutrophil antibodies were negative.

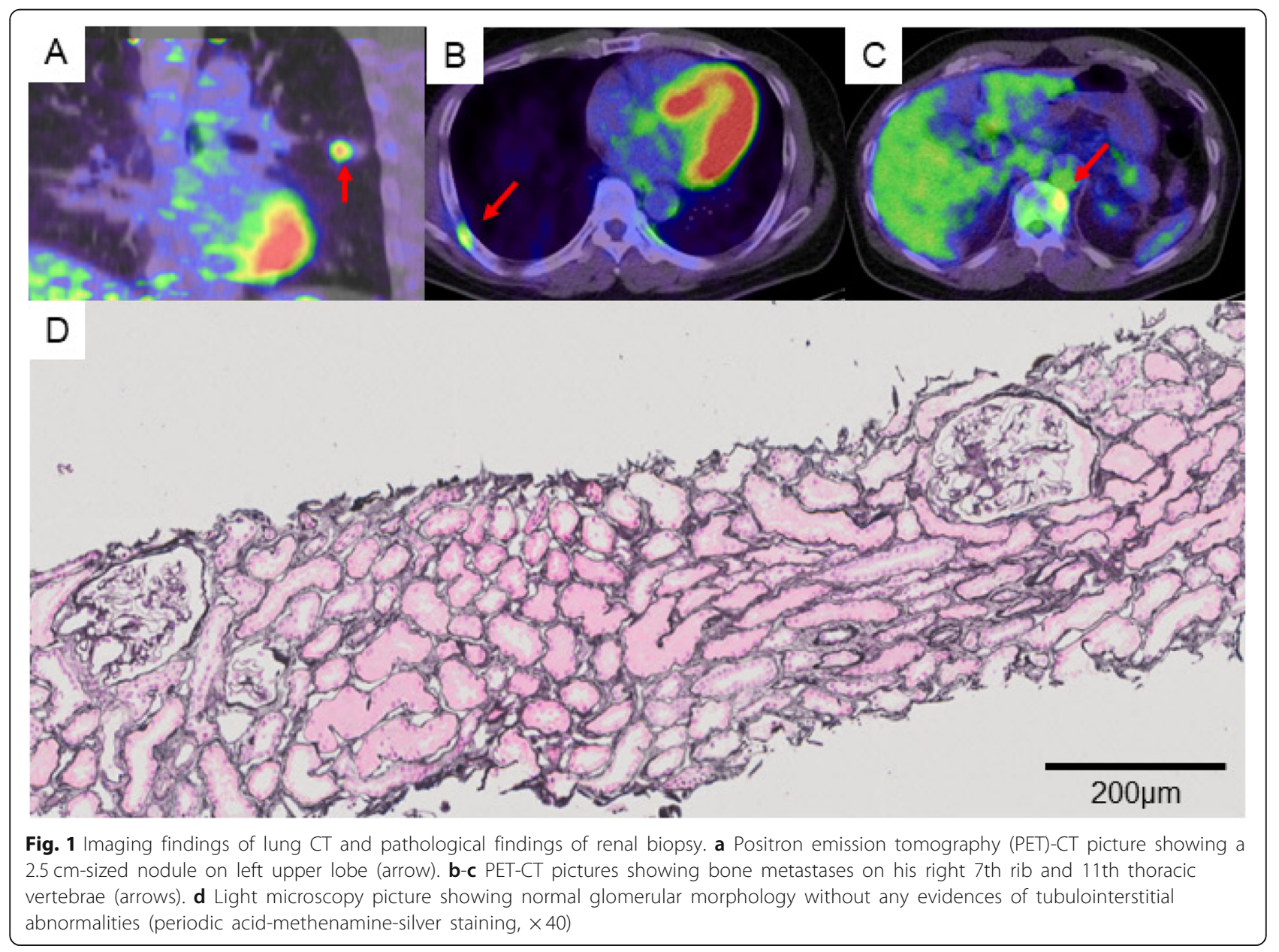




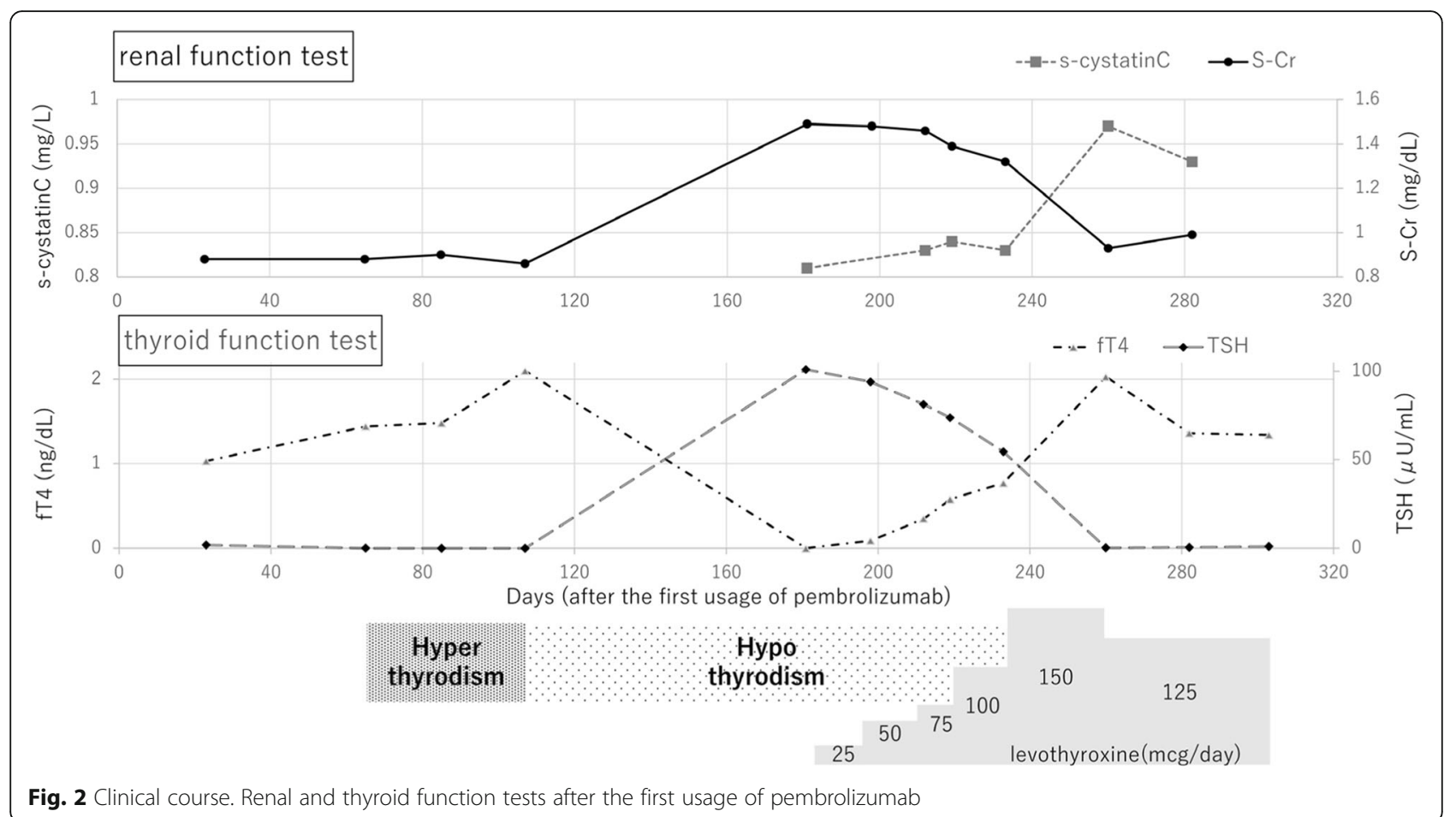

Urinalysis showed neither hematuria nor proteinuria nor an increase in urinary $\beta_{2}$-microglobulin $\left(\beta_{2} M G\right)$ and $N$ acetyl- $\beta$-glucosaminidase (NAG) levels. Gallium-67 scintigraphy showed no uptake in the kidneys. A renal biopsy was performed, which revealed neither glomerular nor tubulointerstitial abnormalities (Fig. 1d), thus denying pembrolizumab-induced tubulointerstitial nephritis and glomerulonephritis.

Retrospective evaluations revealed that the patient had developed asymptomatic hyperthyroidism with antithyroglobulin antibodies $(23 \mathrm{IU} / \mathrm{mL})$ and anti-TSH receptor antibodies (TRAb) $(6.31 \mathrm{U} / \mathrm{l}) 3$ months after the initiation of pembrolizumab, which was followed by asymptomatic hypothyroidism without adrenal insufficiency (Fig. 2). In summary, we diagnosed the patient with pembrolizumab-induced painless thyroiditis. Since the increase in $\mathrm{s}-\mathrm{Cr}$ levels paralleled the decline in free T4 (fT4) levels, we suspected an association between hypothyroidism and increased s-Cr levels. Levothyroxine at a dose of $25 \mu \mathrm{g}$ daily was prescribed and gradually increased. Levothyroxine treatment improved thyroid function tests as well as s-Cr levels, while the levels of scystatin $\mathrm{C}$ were elevated. 24-h Ccr after the improvement of increased s-Cr levels (s-Cr: $1.00 \mathrm{mg} / \mathrm{dl}$, eGFR: $61.5 \mathrm{ml} / \mathrm{min} / 1.73 \mathrm{~m}^{2}$ ) was $50.7 \mathrm{ml} / \mathrm{min}$ and urine creatinine was $1.11 \mathrm{~g} /$ day. Without any abnormalities on renal histology in renal biopsy or any signs of other causes of renal dysfunction, such as hypotension and cargiological abnormalities, we concluded that the increased $\mathrm{s}-\mathrm{Cr}$ levels were most likely caused by the rapid decline of thyroid function during the transition from hyperthyroidism into hypothyroidism induced by pembrolizumab. Pembrolizumab was resumed, and the patient's thyroid and renal function remained normal (Fig. 2).

\section{Discussion and conclusions}

This is the first case of reversible increased s-Cr levels caused by ICI-induced hypothyroidism. Pembrolizumab is a humanized monoclonal anti-PD1 antibody that induces an immune response against tumor tissues. It has been successful in inducing remission in patients with severe metastatic disease, who are often refractory to other chemotherapeutic agents. In refractory NSCLC, pembrolizumab prolongs overall survival and progression-free survival [3]. However, irAEs occur in $20 \%$ of patients on pembrolizumab [4]. One of the most frequent irAEs caused by pembrolizumab is thyroid disorders (hypothyroidism, $8 \%$; hyperthyroidism, 6\%) [4]. It was reported that nephritis occurred in $9(0.3 \%)$ of 2799 patients receiving pembrolizumab, including grade $2(0.1 \%)$, grade $3(0.1 \%)$, and grade 4 $(<0.1 \%)$ nephritis [1]. In the majority of the cases, renal dysfunction under pembrolizumab treatment is due to tubulointerstitial nephritis [2]. Therefore, the cessation of pembrolizumab, renal biopsies, and steroid treatment (prednisolone $1-2 \mathrm{mg} / \mathrm{kg} /$ day) are recommended in cases of grade 2-4 renal failure in the Common Terminology Criteria for Adverse Events (CTCAE) [1]. However, in our case, careful evaluation, including renal biopsy, denied pembrolizumab-induced tubulointerstitial nephritis and revealed that pembrolizumab may 
have caused hypothyroidism-related increase in $\mathrm{s}-\mathrm{Cr}$ levels, which was able to be resolved with levothyroxine treatment; thus, neither steroid therapies nor cessions of pembrolizumab were required.

There is accumulating evidence showing a strong correlation between changes in thyroid status and changes in renal function [5]. It has been reported that $\mathrm{s}-\mathrm{Cr}$ levels decrease $(-17.6 \%)$ in hyperthyroidism compared with those seen with normal thyroid function, whereas an elevation in s-Cr levels is seen in hypothyroidism compared with that seen with normal thyroid function (+11\%) [6]. In addition, a recent study indicated a significant decline in eGFR after patients with hyperthyroidism became euthyroid, suggesting that hyperthyroidism might mask mild renal failure [7]. It has also been reported that eGFR declines in 55\% of adults with hypothyroidism, and thyroid hormone replacement usually resolves renal dysfunction $[8,9]$. Although the detailed mechanisms by which hypothyroidism causes declines in eGFR are still unclear, it is suggested that hypothyroidism might decrease renal function in multiple mechanisms. These include decreased kidney mass [10], reduced renal perfusion pressure because of decreased cardiac output and increased vascular resistance [11-13], reduced sensitivity to the body's sympathetic drive and renin-angiotensin-aldosterone system activity [14], and possible rhabdomyolysis [15]. In addition, it has also been reported that increased s-Cr levels under hypothyroidism might be associated with increased circulating $\mathrm{Cr}$, suggesting hypothyroidism might increase s$\mathrm{Cr}$ levels independent of GFR. These mechanisms include increased release of $\mathrm{Cr}$ from muscle tissue due to myopathy and rhabdomyolysis [16], and increased conversion from creatine into creatinine [17]. Indeed, in our case, re-evaluation of renal function revealed no increase in 24-h Ccr after the levothyroxine treatment despite the apparent improvement in $\mathrm{s}-\mathrm{Cr}$ levels. In addition, a decrease in urine $\mathrm{Cr}$ after the levothyroxine treatment (from $1.8 \mathrm{~g} /$ day to $1.11 \mathrm{~g} /$ day) was observed. These observations suggest that increased $\mathrm{s}-\mathrm{Cr}$ levels under hypothyroidism might be mainly due to the increased $\mathrm{Cr}$ supply rather than due to decreased GFR. Further study is required to uncover the exact mechanisms of increased s-Cr levels under hypothyroidism.

In contrast to the increase in s-Cr levels, the levels of scystatin $C$ levels normally decrease under hypothyroidism [18]. It has been reported that s-cystatin $C$ levels decline in hypothyroidism due to reduced production, consequent to reduced cellular metabolism [18], and this result is different from that seen with other causes of renal dysfunction. Indeed, in our case, s-cystatin $\mathrm{C}$ levels were within the normal range despite the increased s-Cr level on admission, and levothyroxine treatment reversed the increase in s-Cr levels while it elevated s-cystatin C levels.
These findings are compatible with hypothyroidisminduced increase in s-Cr levels. Importantly, both tubulointerstitial nephritis and hypothyroidism-induced increase in s-Cr levels are unlikely to show apparent proteinuria or hematuria; Thus, these two different kinds of pathologies are difficult to differentiate by urinalysis. Therefore, monitoring both $\mathrm{s}-\mathrm{Cr}$ and s-cystatin $\mathrm{C}$ levels might help us differentiate the causes of increased $\mathrm{s}-\mathrm{Cr}$ levels.

Immune-related endocrine toxicities, including thyroid dysfunction, are usually irreversible. Interestingly, overall survival with pembrolizumab was significantly higher in subjects who developed thyroid dysfunction under pembrolizumab treatment than those who did not develop thyroid dysfunction (hazard ratio, 0.29; 95\% confidence interval (CI) $0.09-0.94 ; p=0.04$ ) [8], suggesting these patients might not need to stop permbrolizumab treatment but rather could continue treatment with levothyroxine. Therefore, hypothyroidism during pembrolizumab treatment needs to be recognized quickly and to be treated appropriately so that patients can keep using pembrolizumab and prolong their overall survival. Considering the high frequency of pembrolizumab-induced hypothyroidism, our case is unlikely to be rare, and more similar cases could appear. The number of cases might be underestimated because some cases might be misdiagnosed as tubulointerstitial nephritis and subjected to steroid treatment. Since not so many clinicians are aware that hypothyroidism may cause increased s-Cr levels, it is urgent to highlight possible hypothyroidism-caused increase in $\mathrm{s}-\mathrm{Cr}$ levels, which might be reversed with levothyroxine treatment. Nevertheless, it may take a relatively long time until s-Cr levels return to baseline with the levothyroxine treatment under hypothyroidism-induced increase in s-Cr levels. Indeed, it took approximately 2 months in our case. Since the delay of steroid treatment in tubulointerstitial nephritis could lead to irreversible renal damage, renal biopsy is still am important option to differentiate these causes when physicians are not confident in ruling out the possibility of tubulointerstitial nephritis.

In conclusion, all clinicians involved in ICI treatment need to recognize possible hypothyroidism-caused increase in $\mathrm{s}-\mathrm{Cr}$ levels, which can be reversed with levothyroxine treatment. We propose monitoring scystatin $\mathrm{C}$ levels routinely as well as thyroid function under ICI treatment to differentiate hypothyroidismrelated increase in $\mathrm{s}$-Cr levels from tubulointerstitial nephritis before renal biopsies or steroid treatment are performed.

\section{Abbreviations}

ICls: Immune checkpoint inhibitors; irAEs: immune-related adverse events; NSCLC: Non-small cell lung cancer; EGFR: Epidermal growth factor receptor; ALK: Anaplastic lymphoma kinase; PDL1: Programmed death ligand 1; sCr: serum creatinine; eGFR: estimated glomerular filtration rate; 
CT: Computed tomography; CRP: C-reactive protein; s-cystatin C: serum cystatin C; Ccr: Creatinine clearance; $\beta_{2}$ MG: $\beta_{2}$-microglobin; NAG: N-acetyl- $\beta$ glucosaminidase; TRAb: anti-TSH receptor antibody; fT4: free T4; CTCAE: Common Terminology Criteria for Adverse Events; PET: Positron emission tomography; Cl: Confidence interval

\section{Acknowledgements}

Not applicable.

\section{Authors' contributions}

$N M, K T 1, E I, T H, K F, K T 2$ and $K I$ were the treating physicians of the patient reported. NM, KT1, KF, SK, HS and JW performed the evaluation of the renal biopsy. All authors participated in the discussion of the manuscript and approved the final version.

\section{Funding}

This work was supported by the Japanese Society for the Promotion of Science (JSPS)/Grant-in-Aid for Young Scientists (18 K15978, Kenji Tsuji) for the use of English language editing service.

\section{Availability of data and materials}

All data generated or analysed during this study are included in this published article.

\section{Ethics approval and consent to participate} Not applicable.

\section{Consent for publication}

Written informed consent was obtained from the patient's wife for publication of this Case report and any accompanying images, due to the death of the patient after the oral agreement.

\section{Competing interests}

The authors declare that they have no competing interests.

\section{Author details}

'Department of Nephrology, Rheumatology, Endocrinology and Metabolism, Okayama University Graduate School of Medicine, Dentistry, and Pharmaceutical Sciences, 2-5-1 Shikata-cho, Okayama 700-8558, Japan. ${ }^{2}$ Department of Hematology, Oncology, Allergy and Respiratory Medicine, Okayama University Graduate School of Medicine, Dentistry, and Pharmaceutical Sciences, Okayama, Japan. ${ }^{3}$ Department of Human Resource Development of Dialysis Therapy for Kidney Disease, Okayama University Graduate School of Medicine, Dentistry, and Pharmaceutical Sciences, Okayama, Japan.

Received: 1 July 2019 Accepted: 20 March 2020

Published online: 31 March 2020

\section{References}

1. Inc MC. Keytruda (pembrolizumab) [prescribing information]. NJ: Merck \& CO Inc; 2018. http://www.merck.com/product/usa/pi_circulars/k/keytruda/ keytruda_pi.pdf.

2. Wanchoo R, Karam S, Uppal NN, Barta VS, Deray G, Devoe C, et al. Adverse renal effects of immune checkpoint inhibitors: a narrative review. Am J Nephrol. 2017:45(2):160-9.

3. Herbst RS, Baas P, Kim DW, Felip E, Perez-Gracia JL, Han JY, et al. Pembrolizumab versus docetaxel for previously treated, PD-L1-positive, advanced non-small-cell lung cancer (KEYNOTE-010): a randomised controlled trial. Lancet. 2016;387(10027):1540-50.

4. Kwok G, Yau TC, Chiu JW, Tse E, Kwong YL. Pembrolizumab (Keytruda). Hum Vaccin Immunother. 2016;12(11):2777-89.

5. den Hollander JG, Wulkan RW, Mantel MJ, Berghout A. Correlation between severity of thyroid dysfunction and renal function. Clin Endocrinol. 2005; 62(4):423-7.

6. Verhelst J, Berwaerts J, Marescau B, Abs R, Neels H, Mahler C, et al. Serum creatine, creatinine, and other guanidino compounds in patients with thyroid dysfunction. Metabolism. 1997:46(9):1063-7.

7. Sonmez E, Bulur O, Ertugrul DT, Sahin K, Beyan E, Dal K. Hyperthyroidism influences renal function. Endocrine. 2019;65(1):144-8.
8. Basu G, Mohapatra A. Interactions between thyroid disorders and kidney disease. Indian J Endocrinol Metab. 2012:16(2):204-13.

9. Kreisman SH, Hennessey JV. Consistent reversible elevations of serum creatinine levels in severe hypothyroidism. Arch Intern Med. 1999;159(1):79-82.

10. Vargas F, Moreno JM, Rodriguez-Gomez I, Wangensteen R, Osuna A, Alvarez-Guerra $\mathrm{M}$, et al. Vascular and renal function in experimental thyroid disorders. Eur J Endocrinol. 2006;154(2):197-212.

11. Hammond HK, White FC, Buxton IL, Saltzstein P, Brunton LL, Longhurst JC. Increased myocardial beta-receptors and adrenergic responses in hyperthyroid pigs. Am J Phys. 1987;252(2 Pt 2):H283-90.

12. Walker JD, Crawford FA, Kato S, Spinale FG. The novel effects of 3,5,3'triiodo-L-thyronine on myocyte contractile function and beta-adrenergic responsiveness in dilated cardiomyopathy. J Thorac Cardiovasc Surg. 1994; 108(4):672-9.

13. Celsing F, Blomstrand E, Melichna J, Terrados N, Clausen N, Lins PE, et al. Effect of hyperthyroidism on fibre-type composition, fibre area, glycogen content and enzyme activity in human skeletal muscle. Clin Physiol. 1986; 6(2):171-81.

14. Asmah BJ, Wan Nazaimoon WM, Norazmi K, Tan TT, Khalid BA. Plasma renin and aldosterone in thyroid diseases. Horm Metab Res. 1997;29(11):580-3.

15. Kursat $\mathrm{S}$, Alici T, Colak HB. A case of rhabdomyolysis induced acute renal failure secondary to statin-fibrate-derivative combination and occult hypothyroidism. Clin Nephrol. 2005;64(5):391-3.

16. Norrelund H, Hove KY, Brems-Dalgaard E, Jurik AG, Nielsen LP, Nielsen S, et al. Muscle mass and function in thyrotoxic patients before and during medical treatment. Clin Endocrinol. 1999:51(6):693-9.

17. Wilkins L, Fleischmann W. Effects of thyroid on Creatine metabolism with a discussion of the mechanism of storage and excretion of Creatine bodies. J Clin Invest. 1946;25(3):360-77.

18. Kimmel M, Braun N, Alscher MD. Influence of thyroid function on different kidney function tests. Kidney Blood Press Res. 2012;35(1):9-17.

\section{Publisher's Note}

Springer Nature remains neutral with regard to jurisdictional claims in published maps and institutional affiliations.

\section{Ready to submit your research? Choose BMC and benefit from:}

- fast, convenient online submission

- thorough peer review by experienced researchers in your field

- rapid publication on acceptance

- support for research data, including large and complex data types

- gold Open Access which fosters wider collaboration and increased citations

- maximum visibility for your research: over $100 \mathrm{M}$ website views per year

At BMC, research is always in progress.

Learn more biomedcentral.com/submissions 